\title{
First-trimester medical abortion service in Hong Kong
}

\author{
Sue ST Lo *, PC Ho
}

\section{A B S T R A C T}

Research on medical abortion has been conducted in Hong Kong since the 1990s. It was not until 2011 that the first-trimester medical abortion service was launched. Mifepristone was registered in Hong Kong in April 2014 and all institutions that are listed in the Gazette as a provider for legal abortion can purchase mifepristone from the local provider. This article aimed to share our 3-year experience of this service with the local medical community. Our current protocol is safe and effective, and advocates 200-mg oral mifepristone and 400- $\mu \mathrm{g}$ sublingual misoprostol 24 to 48 hours later, followed by a second dose of 400- $\mu$ g sublingual misoprostol 4 hours later if the patient does not respond. The complete abortion rate is $97.0 \%$ and ongoing pregnancy rate is $0.4 \%$. Some minor side-effects have been reported and include diarrhoea, fever, abdominal pain, and allergy. There have been no serious adverse events such as heavy bleeding requiring transfusion, anaphylactic reaction, septicaemia, or death.

\begin{tabular}{l} 
Hong Kong Med J 2015;21:462-7 \\
\hline DOI: $10.12809 / \mathrm{hkmj} 154525$ \\
${ }^{1}$ SST Lo *, MD, FRCOG \\
${ }^{2}$ PC Ho, FRCOG, FHKAM (Obstetrics and Gynaecology) \\
${ }^{1}$ The Family Planning Association of Hong Kong, 10/F, Southorn Centre, \\
130 Hennessy Road, Wanchai, Hong Kong \\
${ }^{2}$ Department of Obstetrics and Gynaecology, The University of Hong \\
Kong, Pokfulam, Hong Kong \\
${ }^{*}$ Corresponding author: stlo@famplan.org.hk
\end{tabular}

\section{Introduction}

In Hong Kong, legal abortion can be performed in registered institutions in accordance with the legal requirements stipulated in the Offences against the Person Ordinance Cap 212. In the past, firsttrimester pregnancies up to 12 weeks of gestation were terminated by suction evacuation and achieved a complete abortion rate of $99 \%{ }^{1}$ Possible risks and complications, which could affect future fertility, include heavy bleeding, infection, uterine perforation with or without bowel injury, and cervical trauma.

With the introduction of mifepristone, a progesterone antagonist, effective and safe medical abortion became possible. Over the past three decades, various medical abortion protocols have been tested in different countries and Hong Kong has participated in such research since the 1990s. Most institutions recommended the use of mifepristone followed by prostaglandin 24 to 48 hours later to stimulate uterine contraction and expulsion of the conceptus. Mifepristone was first registered for medical abortion in France and China in 1988. By 2013, mifepristone was registered in 60 countries $^{2}$ and was eventually registered in Hong Kong on 8 April 2014 for medical abortion and cervical priming before first-trimester surgical abortion (Mifegyne; Exelgyn, Paris, France). All institutions listed in the Gazette as a legal abortion provider can purchase mifepristone from a local provider. The provider cannot sell mifepristone to an individual doctor or pharmacy store. Although the posology of Mifegyne indicates its use for first-trimester medical abortion up to 63 days of gestation, the treatment is also effective after 63 days of gestation. ${ }^{3}$

Most regulatory bodies, including Hong Kong, approved the use of 600-mg mifepristone for medical abortion but the International Planned Parenthood Federation (IPPF), ${ }^{4}$ World Health Organization (WHO), ${ }^{5}$ and Royal College of Obstetricians and Gynaecologists (RCOG) ${ }^{6}$ recommended the use of $200 \mathrm{mg}$ as it has similar efficacy and lower cost. ${ }^{7}$

A prostaglandin has to be given after mifepristone to stimulate uterine contractions. Misoprostol is the prostaglandin of choice because it is cheap, effective, and stable at room temperature but the dose, route, and timing of administration is not standardised. The WHO and RCOG recommend 800- $\mu$ g misoprostol (vaginal, buccal, or sublingual) 24 to 48 hours later. ${ }^{5,6}$ For women at 50 to 63 days of gestation, the RCOG recommends an additional $400-\mu \mathrm{g}$ misoprostol (vaginal or oral) 4 hours later if abortion has not occurred. ${ }^{6}$ The IPPF recommends 800- $\mu \mathrm{g}$ misoprostol (oral, vaginal, buccal, or sublingual) at once or in two doses 2 hours apart, 36 to 48 hours later. ${ }^{4}$ When compared with vaginal misoprostol, sublingual misoprostol appears to be associated with a higher rate of gastro-intestinal side-effects, and buccal misoprostol appears to be associated with a higher rate of diarrhoea.?

The complete abortion rate for medical 
abortion is approximately 95\%, ${ }^{1}$ which is slightly lower than that for surgical abortion. The chance of ongoing pregnancy is $1 \%$ to $2 \%$ and the baby may suffer from congenital abnormalities due to prostaglandin. Hence it is recommended that suction evacuation be performed if medical abortion fails. Bleeding and abdominal cramps are inevitable side-effects of medical abortion although $<1 \%$ of women need emergency curettage because of excessive bleeding ${ }^{1}$ and $0.1 \%$ require blood transfusion. ${ }^{8}$ In a systematic review of 65 studies with heterogeneous designs, the overall frequency of diagnosed or treated pelvic infection after medical abortion was $0.9 \% .^{9}$ The incidence of suspected or confirmed post-abortion infection (endometritis, pelvic inflammatory disease) quoted in the posology of mifepristone is $<5 \% .{ }^{10}$ Very common and common side-effects of mifepristone include nausea, vomiting, diarrhoea, light or moderate abdominal cramps, post-abortion infection, uterine cramps, and heavy bleeding. ${ }^{10}$ The side-effects of prostaglandin observed during medical abortion include transient fever, chills, nausea, vomiting, diarrhoea, headache, dizziness, and rash. ${ }^{4}$ The incidence and intensity of prostaglandin side-effects are determined by the dose and route of administration.

\section{Our protocols}

The Family Planning Association of Hong Kong (FPAHK) piloted a medical abortion service for gestation up to 63 days in November 2011. Routine ultrasound examination was performed to ascertain the gestation and to exclude multiple pregnancies and ectopic pregnancy. Exclusion criteria included hypersensitivity to mifepristone or misoprostol, multiple pregnancies, haemoglobin level of $<100 \mathrm{~g} / \mathrm{L}$, bleeding tendency, known coagulopathy, use of anticoagulant, current long-term systemic corticosteroid therapy, history of adrenal tumour/ steroid-dependent tumour, chronic adrenal failure, porphyria, renal/liver impairment, cardiovascular disease (including arrhythmia, angina, heart failure, Raynaud's disease, diastolic hypertension of $>95 \mathrm{~mm} \mathrm{Hg}$, arterial hypotension, history of evidence of thromboembolism), epilepsy, on multiple medications, inherited porphyria, severe asthma uncontrolled by therapy, and breastfeeding.

The initial protocol was 200-mg oral mifepristone followed by $800-\mu \mathrm{g}$ vaginal misoprostol 48 hours later (protocol 1, $n=603$ ). Both doses were administered in the FPAHK. The woman was permitted to leave after mifepristone administration provided she did not feel unwell but was required to remain for observation on the day of misoprostol administration. Oral paracetamol, oral mefenamic acid, and intramuscular pethidine were offered for pain relief. Vital signs, hydration status, and blood loss were monitored. Most women passed tissue

\section{香港的藥物終止早期懷孕服務 羅善清、何柏松}

香港自九十年代開始已經展開有關藥物終止懷孕的研究工作, 直至 2011 年才引入藥物終止早期懷孕服務。米非司酮 (mifepristone) 在 2014年4月已獲註冊並在香港銷售, 意味着本港所有提供合法墮胎服 務的機構均可從本地供應商購買此藥品。本文旨在與本地醫護界分享 三年來提供藥物終止早期懷乃的經驗。香港家庭計劃指導會所採用的 藥物終止早期懷乃方法, 是讓病人口服米非司酮 $200 \mathrm{mg}$, 然後在 24 到48小時後舌下含服米索前列醇片（misoprostol） $400 \mu \mathrm{g}$ 。4個小時 後若病人未對此劑量產生反應, 會再於舌下含服第二劑米索前列醇 片 $400 \mu \mathrm{g}$; 這種方法既安全又有效。藥物終止早期懷乃的成功率為 $97.0 \%$, 持續性懷乃率為 $0.4 \%$ 。過往紀錄顯示病人有輕微副作用, 包 括腹瀉、發燒、腹痛和藥物過敏, 而直至目前為止未有嚴重不良事件 發生, 如大量出血而須輸血、過敏反應、敗血症甚至死亡

mass within 4 hours of misoprostol administration. The doctor routinely performed a pelvic examination after 4 hours to remove any tissue mass remaining in the vagina, and to assess blood loss and vital signs. Any tissue mass collected was sent for pathological examination to exclude partial mole. The patient was discharged provided bleeding was not excessive.

In January 2013, this protocol was changed to 200-mg oral mifepristone followed by $400-\mu \mathrm{g}$ sublingual misoprostol 48 hours later (protocol 2, $n=890)$. We changed from vaginal to sublingual administration because vaginal administration is intrusive, and requires more consultation time and more medical consumables. Sublingual administration requires the woman to place two tablets of misoprostol under her tongue and then swallow after 30 minutes. We used a half dose (400 $\mu \mathrm{g})$ to minimise the severity of gastro-intestinal reactions that might make patients uncomfortable and increase the workload of nursing and auxiliary staff. Since November 2013, women have been given a second dose of 400- $\mathrm{gg}$ sublingual misoprostol if abortion has not occurred within 4 hours of misoprostol administration (protocol 3, $n=1042$ ). We hope this regimen will reduce the ongoing pregnancy rate by administration of the full dose to selected patients.

Surgical evacuation is performed if there is heavy bleeding after misoprostol. Manual vacuum aspiration was introduced as an alternative to electric vacuum aspiration in January 2014.

Women return for follow-up after 1 week if abortion has not started on discharge. Other women are followed up 2 to 3 weeks after the abortion. Ultrasound examination is performed in the presence of any abnormal symptoms or signs. Suction evacuation is arranged for ongoing 
pregnancy. Prior to the introduction of $400-\mu \mathrm{g}$ sublingual misoprostol after November 2013 (protocol 3), those with persistent bleeding/spotting and/or retained products of gestation were managed expectantly or by curettage. An additional dose of misoprostol is not offered to women with a history of caesarean section. Further follow-up is arranged as required, with final follow-up 6 to 8 weeks after abortion to confirm return of menstruation and assess their compliance with contraception.

Women are encouraged to start birth control immediately after misoprostol administration. Hormonal injectables are given on discharge. Women are asked to start oral pills on the evening after misoprostol. A condom should be used consistently and correctly thereafter. Insertion of an intrauterine contraceptive device cannot be performed until abortion has completed and is usually done at the 6-week follow-up.

\section{Outcome}

Overall, 2535 medical abortions in 2499 women were performed in the 3 years from 2011 to 2014 . The median age was 27 years (interquartile range, 11 years). Most women were nulliparous $(63.8 \%)$, and mean parity was 0.61 (standard deviation, 0.9$)$. Most women had no history of surgical $(73.1 \%)$ or medical (95.1\%) abortion. The demographics are detailed in Table 1.

Five women took mifepristone only, without misoprostol. One woman developed palmar erythema and intense itching 30 minutes after vaginal misoprostol administration: misoprostol tablets were removed and douching performed. Allergic signs and symptoms resolved 15 minutes later. Suction evacuation was subsequently performed on that day. This was the 84th case when doctors were still relatively inexperienced and might have overreacted to her symptoms. One woman was admitted to hospital for abdominal pain after mifepristone: ultrasound examination revealed complete abortion and she was not given misoprostol during admission. Another woman was admitted to hospital because of vaginal bleeding: emergency curettage was performed. Two women were admitted to hospital because of persistent vomiting with dehydration. They did not attend the appointment for misoprostol and suction evacuation was arranged.

Among 2530 cases admitted for misoprostol, $17(0.7 \%)$ underwent emergency suction evacuation because of heavy bleeding after misoprostol administration with 11 having gestation of 56 days and above. Bleeding stopped after curettage in all women. The outcomes of medical abortion are listed in Table 2. After excluding 159 women who did not return for follow-up, the overall complete abortion rate was $97.0 \%$. The complete abortion rate in those with gestation of $\geq 56$ days was significantly lower
TABLE I. Demographic characteristics of women undergoing medical abortion $(n=2535)$

\begin{tabular}{|c|c|}
\hline Demographic characteristic & No. $(\%)$ of cases \\
\hline \multicolumn{2}{|l|}{ Age (years) } \\
\hline $14-20$ & $453(17.9)$ \\
\hline $21-30$ & 1250 (49.3) \\
\hline $31-40$ & $706(27.8)$ \\
\hline $41-47$ & $126(5.0)$ \\
\hline \multicolumn{2}{|l|}{ Education attained } \\
\hline Illiterate & $13(0.5)$ \\
\hline Primary & $40(1.6)$ \\
\hline Secondary & $1614(63.7)$ \\
\hline Undergraduate and above & 868 (34.2) \\
\hline \multicolumn{2}{|l|}{ Relationship status } \\
\hline Unmarried & $1570(61.9)$ \\
\hline Married & 855 (33.7) \\
\hline Separated/divorced & $96(3.8)$ \\
\hline Widowed & $14(0.6)$ \\
\hline \multicolumn{2}{|l|}{ Parity } \\
\hline 0 & $1618(63.8)$ \\
\hline 1 & 417 (16.4) \\
\hline 2 & $406(16.0)$ \\
\hline 3 & $75(3.0)$ \\
\hline 4 & $15(0.6)$ \\
\hline $5-7$ & $4(0.2)$ \\
\hline \multicolumn{2}{|l|}{ Previous No. of surgical abortion } \\
\hline 0 & $1852(73.1)$ \\
\hline 1 & $470(18.5)$ \\
\hline 2 & $152(6.0)$ \\
\hline 3 & 49 (1.9) \\
\hline 4 & $12(0.5)$ \\
\hline \multicolumn{2}{|l|}{ Previous No. of medical abortion } \\
\hline 0 & $2411(95.1)$ \\
\hline 1 & $113(4.5)$ \\
\hline 2 & $11(0.4)$ \\
\hline \multicolumn{2}{|l|}{$\begin{array}{l}\text { Contraceptive used before the index } \\
\text { pregnancy }\end{array}$} \\
\hline Coitus interruptus & $97(3.8)$ \\
\hline Condom / diaphragm & $1886 / 1(74.4)$ \\
\hline $\begin{array}{l}\text { Combined hormone pill / patch / } \\
\text { injectable }\end{array}$ & 83 / 2 / 6 (3.6) \\
\hline Emergency contraceptive pill & $20(0.8)$ \\
\hline Intrauterine contraceptive device & $3(0.1)$ \\
\hline Progestogen-only pill / injectable & $3 / 2(0.2)$ \\
\hline Safety period & $56(2.2)$ \\
\hline Spermicide & $3(0.1)$ \\
\hline Vasectomy & $1(0.04)$ \\
\hline No contraceptive & $372(14.7)$ \\
\hline
\end{tabular}


TABLE 2. Outcomes of women who had completed the course of medical abortion using mifepristone and misoprostol

\begin{tabular}{|c|c|c|c|c|}
\hline \multirow[t]{2}{*}{ Outcome } & \multicolumn{4}{|c|}{ No. (\%) of cases } \\
\hline & Total $(n=2530)$ & $\begin{array}{l}\text { Protocol } 1 \\
(n=600)\end{array}$ & $\begin{array}{l}\text { Protocol } 2 \\
(n=890)\end{array}$ & $\begin{array}{l}\text { Protocol } 3 \\
(n=1040)\end{array}$ \\
\hline Complete abortion & $2301\left(97.0^{\star}\right)$ & $548\left(96.3^{\star}\right)$ & $813\left(97.5^{\star}\right)$ & $940\left(97.1^{*}\right)$ \\
\hline Ongoing pregnancy & $10\left(0.4^{\star}\right)$ & $5\left(0.9^{\star}\right)$ & $3\left(0.4^{\star}\right)$ & $2\left(0.2^{\star}\right)$ \\
\hline No. of curettage performed & $55\left(2.3^{*}\right)$ & $15\left(2.6^{\star}\right)$ & $18\left(2.2^{\star}\right)$ & $22\left(2.3^{\star}\right)$ \\
\hline $\begin{array}{l}\text { Referred to hospital for further investigations and management for } \\
\text { persistent bleeding / RPOG; outcome unknown }\end{array}$ & $5(0.2)$ & $1(0.2)$ & 0 & $4(0.4)$ \\
\hline Did not return for follow-up & $159(6.3)$ & $31(5.2)$ & $56(6.3)$ & $72(6.9)$ \\
\hline
\end{tabular}

Abbreviation: $\mathrm{RPOG}=$ retained products of gestation

* Excluded women who defaulted follow-up

TABLE 3. Minor side-effects requiring treatment

\begin{tabular}{|c|c|c|c|c|c|}
\hline \multirow[t]{2}{*}{ Treatment } & \multicolumn{4}{|c|}{ No. $(\%)$ of cases } & \multirow[t]{2}{*}{$P$ value } \\
\hline & Total $(n=2530)$ & $\begin{array}{l}\text { Protocol } 1 \\
(n=600)\end{array}$ & $\begin{array}{c}\text { Protocol } 2 \\
(n=890)\end{array}$ & $\begin{array}{c}\text { Protocol } 3 \\
(n=1040)\end{array}$ & \\
\hline Paracetamol $1 \mathrm{~g}$ for pain relief & $498(19.7)$ & $133(22.2)$ & $216(24.3)$ & $149(14.3)$ & $<0.001$ \\
\hline Mefenamic acid $500 \mathrm{mg}$ for pain relief & $2(0.1)$ & $2(0.3)$ & 0 & 0 & - \\
\hline Intramuscular pethidine $(1 \mathrm{mg} / \mathrm{kg})$ for pain relief & $5(0.2)$ & $3(0.5)$ & $1(0.1)$ & $1(0.1)$ & - \\
\hline Paracetamol for fever of $>38^{\circ} \mathrm{C}$ & $218(8.6)$ & $52(8.7)$ & $64(7.2)$ & $102(9.8)$ & 0.123 \\
\hline Antibiotics for suspected pelvic infection & $53(2.1)$ & $11(1.8)$ & $20(2.2)$ & $22(2.1)$ & 0.859 \\
\hline Treatment for allergy & $50(2.0)$ & $15(2.5)$ & $21(2.4)$ & $14(1.3)$ & 0.161 \\
\hline Anti-diarrhoeal drug & 0 & 0 & 0 & 0 & \\
\hline Fluid rehydration & 0 & 0 & 0 & 0 & \\
\hline
\end{tabular}

than in those with $<56$ days of gestation $(95.7 \%$ vs 97.7\%; Fisher's exact test, $\mathrm{P}=0.007)$. The complete abortion rate for protocols 1, 2, and 3 was 96.3\%, $97.5 \%$, and $97.1 \%$ respectively, and the respective mean gestation was 51.3 days, 51.7 days, and 51.3 days $(\mathrm{P}=0.362)$. The complete abortion rate did not differ by protocol $(\mathrm{P}=0.440)$, parity $(\mathrm{P}=0.527)$, or history of miscarriage and termination of pregnancy $(\mathrm{P}=0.246)$. Among those who had curettage after medical abortion, $64 \%$ were performed within the first 2 weeks, $14 \%$ were between third and fourth week, and the remaining $22 \%$ were between fifth and 12th week. Curettage within the first 4 weeks was performed for excessive bleeding: those performed later were for retained products of gestation and persistent spotting.

The overall ongoing pregnancy rate was $0.4 \%$ and gestation was between 52 and 60 days. The ongoing pregnancy rate for protocols 1,2 , and 3 was $0.9 \%, 0.4 \%$, and $0.2 \%$, respectively $(\mathrm{P}=0.138)$. After changing to protocol 3, 97 (9.3\%) women received a second dose of misoprostol. During follow-up, 49 women received additional misoprostol-seven during first follow-up for dead fetus in situ, 37 during first 2 weeks for moderate bleeding, one during the fourth week for persistent bleeding, and four for retained products between fourth and eighth week. One required manual vacuum aspiration in the 12th week because of persistent tissue mass despite misoprostol.

Minor side-effects that required treatment are listed in Table 3. Treatment for allergic symptoms of varying severity was required in 50 (2.0\%) cases. One woman developed back and neck rash after mifepristone and was given oral chlorpheniramine maleate $4 \mathrm{mg}$ when she was admitted for misoprostol. Another woman also reported skin rash after mifepristone that resolved spontaneously and no treatment was required. One or more of the following minor allergic symptoms developed in 94 women after misoprostol: palmar erythema, palmar itchiness, perioral rash, and peri-orbital rash. Symptoms resolved spontaneously in 51 women and 43 required oral chlorpheniramine maleate. Two women received oral chlorpheniramine maleate followed by intramuscular chlorpheniramine maleate $10 \mathrm{mg}$ because symptoms progressed: in both cases a localised body rash progressed and 
one woman became breathless. Three women received intramuscular chlorpheniramine maleate: one had generalised body rash with shortness of breath, another had generalised facial rash, and the third developed swollen lips and tongue and palmar erythema with itchiness. One woman developed peri-orbital rash with swelling and blurred vision: intramuscular chlorpheniramine maleate was administered. One hour later, her vision normalised but peri-orbital rash with swelling persisted. Symptoms gradually resolved following intramuscular injection of hydrocortisone $100 \mathrm{mg}$.

During follow-up, 53 (2.1\%) women were treated with oral antibiotics for clinically suspected pelvic infection-11 (1.8\%) had received vaginal misoprostol and $42(2.2 \%)$ had sublingual misoprostol (Table 3 ). Some were treated by their private gynaecologists and others by doctors in the Hospital Authority when they were admitted for bleeding or abdominal pain. Those who were treated by us during follow-up presented with pelvic excitation tenderness with or without prolonged spotting or bleeding. None of them had fever. Empirical antibiotics were prescribed but no swabs were taken for culture. Four $(0.2 \%)$ cases of partial mole were reported by the pathologist and these women were referred to a specialist gynaecology clinic of the Hospital Authority. Two women had post-abortion anaemia due to prolonged bleeding for over 4 weeks, with haemoglobin levels of $80 \mathrm{~g} / \mathrm{L}$ and $86 \mathrm{~g} / \mathrm{L}$. In no case was bleeding sufficiently severe to warrant transfusion, and there were no instances of anaphylactic reaction, septicaemia, or death.

Following abortion, the three main contraceptives of choice were male condom (38.1\%), combined oral contraceptive pill (36.2\%), and combined hormone injection (12.3\%).

\section{Discussion}

When we first piloted the service, we adopted the standard protocol of 200-mg oral mifepristone plus $800-\mu \mathrm{g}$ vaginal misoprostol. The side-effects, complete abortion rate, and ongoing pregnancy rate were as expected. After changing to sublingual administration, the complete abortion rate was similar and the ongoing pregnancy rate was halved that of vaginal misoprostol. This was not a formal study, hence women were not asked to record the intensity of pain, diarrhoea, or discomfort. Nonetheless, the incidence of side-effects for each of the three protocols appears to be similar. Fewer women treated according to protocol 3 required pain relief but the underlying reasons are unclear. The change from protocol 1 to 2 to 3 reduced the ongoing pregnancy rate but the difference was not statistically significant, probably because of the low incidence of ongoing pregnancy. We are continuing to use protocol 3 because it may achieve the best clinical result without increasing patient discomfort. Our nursing staff did not perceive any requirement for increased patient care after changing to sublingual misoprostol. Although one more dose of misoprostol was given in protocol 3, this applied to $<10 \%$ of patients and did not adversely affect nursing workload. In addition, auxiliary staff did not report any increased need for cleaning after changing to sublingual misoprostol. All patients, including those treated with protocol 3, can be discharged before the ward closes at $5 \mathrm{pm}$.

Unlike a research protocol, there is no time limit for performing surgical curettage during followup for incomplete medical abortion. Curettage is recommended if a moderate amount of blood is found in the vagina during speculum examination at follow-up, when prolonged bleeding causes anaemia or if tissue mass is present after 6 weeks. Patients can also request curettage if persistent bleeding is inconvenient.

Those who do not pass tissue mass after misoprostol are followed up after 1 week with routine pelvic ultrasound. Those with a live fetus, ie ongoing pregnancy, will undergo suction evacuation. Occasionally, a dead fetus is detected. During the initial phase of service delivery, doctors arranged curettage to remove the dead fetus. Our doctors are accustomed to surgical abortion and hence are anxious to clear any retained products. At our case discussions, they are reassured that retained products of gestation, even a dead fetus, is part of the natural process of medical abortion and they can try expectant management first. In most cases, watchful waiting and subsequent follow-up 2 weeks later will reveal that the fetus has gone. With the adoption of protocol 3, the option of an additional dose of misoprostol can be offered alongside expectant management.

Collecting tissue mass passed and sending it for pathological examination is important as a partial mole cannot be diagnosed by ultrasound. The incidence of partial mole is similar to that reported in women undergoing surgical abortion in the FPAHK. Follow-up is important because the failure rate for medical abortion is higher than that for surgical abortion, and misoprostol is potentially teratogenic. The follow-up visits also provide an opportunity to evaluate contraceptive use. To prevent further unplanned pregnancies, contraceptive counselling is provided at each visit. The consistent use of contraceptive is emphasised and women are encouraged to discuss any problems they experience with contraception to maximise compliance.

\section{Conclusion}

A medical abortion service can be safely provided in a non-hospital setting that also provides emergency suction evacuation. 


\section{References}

1. Medical management of first-trimester abortion. Contraception 2014;89:148-61.

2. Medical abortion overview. Available from: http://gynuity. org/programs/more/overview/. Accessed 10 Dec 2014.

3. Pazol K, Creanga AA, Zane SB, Burley KD, Jamieson DJ; Centers for Disease Control and Prevention (CDC). Abortion surveillance-United States, 2009. MMWR Surveill Summ 2012;61:1-44.

4. First trimester abortion guidelines and protocols. International Planned Parenthood Federation; 2008.

5. Safe abortion: technical and policy guidance for health systems. 2nd ed. Geneva: World Health Organization; 2012.

6. The care of women requesting induced abortion: evidence- based clinical guideline No. 7. London: Royal College of Obstetricians and Gynaecologists Press; 2011.

7. Kulier R, Kapp N, Gülmezoglu AM, Hofmeyr GJ, Cheng L, Campana A. Medical methods for first trimester abortion. Cochrane Database Syst Rev 2011;(11):CD002855.

8. Raymond EG, Shannon C, Weaver MA, Winikoff B. First-trimester medical abortion with mifepristone 200 mg and misoprostol: a systematic review. Contraception 2013;87:26-37.

9. Shannon C, Brothers LP, Philip NM, Winikoff B. Infection after medical abortion: a review of the literature. Contraception 2004;70:183-90.

10. Mifegyne. Physician leaflet. Exelgyn, France. HK-62757. 8 Apr 2014. 